\title{
A representação de mulheres nos espaços de poder e a standpoint theory: contribuições de uma epistemologia feminista
}

The representation of women in the spaces of power and the standpoint theory: contributions of a feminist epistemology

Marina França Santos ${ }^{1}$

Resumo: O presente trabalho objetiva discutir e analisar criticamente a representação de mulheres nos espaços de poder. $\mathrm{O}$ estudo adota como ferramenta analítica a standpoint theory, epistemologia feminista crítica às concepções tradicionais da teoria do conhecimento, e tem por marco teórico as reflexões trazidas pela teoria democrática sobre inclusão social nos espaços de poder.

Palavras-chave: Epistemologia feminista; Standpoint Theory, Representação, Diversidade de Gênero; Teoria Democrática.

\begin{abstract}
The present article aims to discuss and critically analyze the representation of women in the spaces of power. The study adopts as analytical tool the standpoint theory, a feminist epistemology that criticises the traditional conceptions of the theory of knowledge. The main theoretical framework draws on the reflections brought by the democratic theory about the social inclusion in the spaces of power.

Keywords: Feminist Epistemology; Standpoint Theory; Representation; Gender Diversity; Democratic Theory.
\end{abstract}

\section{Introdução: críticas feministas à epistemologia positivista}

O positivismo trouxe ao conhecimento científico uma tentativa de superação dos pensamentos teológicos e metafísicos e uma postura baseada na observação dos fatos. Esses pilares foram sintetizados por Auguste Comte, a partir da afirmação de que "toda proposição que não seja estritamente redutível ao simples enunciado de um fato, particular ou geral, não pode oferecer nenhum sentido real e inteligível” (COMTE, 1973, p.55). O conhecimento dependeria, assim, do método de investigação das 
ciências naturais, erigindo-se a ciência como a única ferramenta de conhecimento possível da realidade.

A epistemologia positivista defende a possibilidade de um conhecimento universalizável, verdadeiro e objetivo, construído a partir do necessário distanciamento do sujeito cognoscente do objeto investigado, que deve ser isolado de seu contexto (DURKHEIM, 1973, p.411) e observado a partir de um olhar exteriorizado e isento de qualquer tipo de subjetividade. Do pesquisador é exigida uma postura neutra e objetiva no processo de conhecimento, o que significa, nos termos expostos por Durkheim, "afastar sistematicamente todas as noções prévias" (DURKHEIM, 1973, p.404). Só é passível de se tornar ciência o conhecimento cuja produção seja pautada pela neutralidade axiológica.

O sujeito que produz o conhecimento é, nesse contexto, definível como alguém desinteressado, desvinculado emocionalmente do objeto investigado e desprovido de perspectivas, transcendendo sua visão qualquer posição particular ou concreta. A noção de objetividade sustentada pela epistemologia positivista se assenta, pois, em uma dicotomia sujeito/objeto, supostamente hábil a garantir que as representações do mundo independam do sujeito cognoscente (ANDERSON, 2004).

Vê-se claramente que, tomando-se como verdadeiras essas premissas, torna-se completamente indiferente, para a ciência, quem é o sujeito produtor de conhecimento. Na verdade, pode-se considerar até prejudicial que esse sujeito possa ser identificado em suas características pessoais, uma vez que o que se pretende é, ao contrário, o apagamento de sua identidade. Para a epistemologia positivista, portanto, grande responsável pela ideia de ciência hegemônica praticada até os dias de hoje, é irrelevante que sujeitos produtores de conhecimento sejam homens ou mulheres.

O questionamento da epistemologia tradicional tem recebido contribuições de várias vertentes como a psicanálise, a teoria crítica marxista, o desconstrutivismo, o pós-modernismo e os estudos feministas, que, em comum, confrontam o problema da noção de sujeito universal e transcendental pressuposta no conceito de racionalidade da ciência 
ocidental moderna. As epistemologias feministas ${ }^{2}$, de modo específico, para além da simples denúncia da supressão e da invisibilidade das mulheres na produção do conhecimento - o que, como contrapôs Elizabeth Grosz (1995, p.86), por se tratar de exclusão estruturadora dos discursos tradicionais, não se resolve pela simples inclusão de mulheres nas teorias -, centra-se, de uma forma ainda mais profunda, na investigação da "maneira como a diferença sexual opera no plano da organização e funcionamento dos discursos” (RABENHORST, 2011, p.18) e no questionamento da histórica indiferença do saber tradicional em relação ao sistema sexo/gênero.

Nos termos também apontados por Beauvoir, é possível e necessário perceber a ocorrência de uma dinâmica histórica de exclusão das mulheres dos processos de produção do conhecimento (BEAUVOIR, 2009, p.20). Como consequência dessa segregação, pode-se observar o alijamento das mulheres da representação do próprio mundo, já que no momento em que passam a ser admitidas na esfera pública, essa já está constituída como espaço político integralmente pertencente aos homens (BEAUVOIR, 2009, p.21). Todas essas considerações tornam imprescindível indagar - e daí a crucial importância das epistemologias feministas -, quem são os autores dos discursos dominantes nas esferas públicas, a quem esses discursos são dirigidos e qual é a posição das mulheres dentro deles (RABENHORST, 2011).

A ausência ou o diminuto destaque dado às mulheres na história da produção de saberes e de poderes (na ciência, na política e também no direito) são justificados e produzidos por meio de discursos pautados por estereótipos e dualismos de gênero. Os argumentos essencialistas forjados nesse sentido cuidaram tradicionalmente de associar as condições físicas femininas, sejam os ciclos reprodutivos, seja a dimensão de seus órgãos ["era inútil, argumentavam muitos biólogos, que as mulheres buscassem se igualar intelectualmente aos homens através da aquisição da mesma educação: elas simplesmente não dispunham de cérebros suficientemente grandes" (SAYERS, 1987, p.173, tradução nossa)], a uma impossibilidade científica. Esses argumentos, nitidamente disparatados, permanecem sendo postos, porém, com outros conteúdos, mas com as mesmas vestes

\footnotetext{
${ }^{2}$ Assim como são vários os feminismos, são várias as epistemologias feministas que, em comum, reúnem a defesa da relação mútua e necessária entre teoria científica e práxis política e a busca por uma nova concepção de objetividade científica (RABENHORST, 2009, p.28).
} 
científicas, nos dias de hoje. Vale notar as frequentes pesquisas sobre diferenças cerebrais entre homens e mulheres ["a ideia de que uma maior taxa de testosterona fetal cria um cérebro "masculino", superior em coisas tidas como masculinas, como ciência e matemática, enquanto a taxa mais baixa leva a um sensível cérebro "feminino"” (FINE, 2010, p.106, tradução nossa)], que têm sido confrontadas, em seus próprios pressupostos e métodos, por várias cientistas amparadas pelo instrumental crítico feminista, como Rebecca Jordan-Young (2010) e Cordelia Fine (2010).

A principal contribuição proveniente das críticas feministas à epistemologia positivista, desse modo, é o reconhecimento dos efeitos de se ignorar o impacto do sistema sexo/gênero na produção do conhecimento e de se sustentar a existência ou a possibilidade do universal ou do neutro. Apontam os estudos feministas que, ao fazê-lo, o que os padrões de normatividade da ciência, na verdade, estão concretizando é a eleição de conceitos identitários (no caso aqui trabalhado, o masculino, mas também branco, cisgênero, heterossexual, etc) e a perpetuação das diferenças de gênero e das relações de poder de que são constituídas. Os estudos epistemológicos feministas apontam, assim, para a necessidade de se deixar aberto o espaço, nos métodos tradicionais de produção do conhecimento, para perguntas incômodas, desde as que apontam a seletividade dos problemas escolhidos, até as que visam investigar como o gênero influencia as concepções de conhecimento, os próprios sujeitos do conhecimento e as práticas de investigação e de justificação do método científico (ANDERSON, 2004, p.1). Trata-se, desse modo, de uma tentativa de "minar a imagem abstrata, racionalista e universal da teoria científica, recorrendo a estratégias diversificadas” (NARAYAN, 1997, p.277), como o reconhecimento da relação entre valores, emoções e atividades cognitivas e a crítica aos dualismos típicos do pensamento filosófico e jurídico ocidentais. Rompe-se, finalmente, com um cenário valorativo em que a razão, a cultura e o universal são identificados com a ciência, a racionalidade e a masculinidade, enquanto a emoção, a natureza e o particular são mitigados com o rótulo do não-científico e do feminino (NARAYAN, 1997, p.277). 
908 | Veritas | Porto Alegre, v. 62, n. 3, set.-dez. 2017, p. 904-933

\section{A standpoint theory}

A construção feminista da standpoint theory insere-se na proposta de busca pela reflexão sobre as relações existentes entre os sistemas de ideias e as estruturas sociais de que partem (HIRSH; OLSON, 1995, p.212). Opõe, assim, à ficção de um indivíduo "a-situado" e universal, a afirmação de que o gênero do sujeito impacta na sua produção do conhecimento e, por conseguinte, deve ser considerado para a construção de reflexividades, de objetividades e de métodos mais fortes (HIRSH; OLSON, 1995, p.193-194). A standpoint theory provoca, portanto, o retorno e a expansão do domínio dos métodos científicos para o "contexto da descoberta" em vez de restringi-lo ao "contexto de justificação" ${ }^{3}$. Ressalta, assim, a divisão entre saberes majoritários, propagadores dos interesses daqueles que possuem uma posição dominante socialmente, e saberes minoritários, produzidos por aqueles que se situam em posições desvalorizadas e desempoderadas na sociedade, revelando, assim, aquilo que conta e o que não conta como conhecimento científico (RABENHORST, 2011, p.29).

Dialogando, de modo geral, com a sociologia do conhecimento, com a epistemologia e com a filosofia política ${ }^{4}$, a standpoint theory feminista possui como foco a perspectiva do oprimido, elegendo, porém, como objeto de análise, uma perspectiva específica que é a decorrente da opressão de gênero sofrida pelas mulheres. A proposta veiculada é que a posição de exclusão vivenciada pelas mulheres em uma sociedade estruturada sobre o signo da desigualdade de gênero permite o acesso a determinados aspectos da opressão que não são facilmente inteligíveis pelos sujeitos que não se encontram nesse lugar na dinâmica social. A condição de oprimido permite que se perceba, direta e mais facilmente, questões como o ocultamento da opressão em normas sociais apresentadas como construções objetivas, a sutileza e a penetrabilidade da opressão cotidiana e até mesmo o travestimento da opressão em humor e a forma como a opressão por ele persiste (BARTLETT, 2012, p.104). Enquanto outros sujeitos podem compreender, intelectualmente, o

\footnotetext{
3 “(...) estender o domínio dos métodos científicos até o "contexto de descoberta" em vez de restringi-lo ao "contexto de justificação" (HARDING, 2001, p.519, tradução nossa).

${ }^{4}$ A standpoint theory também tem como inspiração, entre outros, a dialética hegeliana do senhor e do escravo (HARTSOCK, 1983, p.296-298) e a crítica marxista à dominação de classe (HARDING, 2004, p.2.).
} 
processo de exclusão, o oprimido vivencia, ainda antes dessa reflexão, a própria dor e as violências perpetradas especificamente em razão desse processo, acompanhadas do silenciamento dos discursos que o evidenciam.

O lugar/posição, e não o sujeito, é a categoria analítica e epistemológica adotada pela standpoint theory a partir da qual perspectivas específicas são elaboradas. Parte-se do pressuposto coerente de que as visões de mundo se apresentam desigualmente posicionadas: as visões dos grupos dominantes estruturam as relações materiais de tal forma que todos os demais são sujeitos a delas compartilhar, não sendo possível simplesmente descartá-las como falsas. As visões dos grupos oprimidos, por consequência, precisam ser conquistadas e a compreensão da persistência dessa lacuna na produção do conhecimento releva a desumanidade de relações sociais, apontando para além do presente e carregando um papel historicamente libertador (HARTSOCK, 1983, p.285). Deve-se, portanto, considerar que, do mesmo modo que o gênero não é condição naturalmente decorrente do sexo, o lugar, ou a posição, do sujeito não é imediatamente ou necessariamente apreendido da sua condição corpórea ou de sua localização espacial, social e cultural.

O entendimento compartilhado da localização ou da posição social subjetiva consiste em um conhecimento alcançado, e não simplesmente dado, exigindo reflexão sobre as estruturas de poder da sociedade e sobre as relações dessas estruturas com os grupos que a compõem (ANDERSON, 2004, p.14-15). Essa posição parece ser acolhida também por Haraway, ao argumentar que a standpoint theory não propõe uma visão romantizada nem uma posição "inocente" (HARAWAY, 1995, p.22-23) em relação à condição das mulheres na sociedade. Uma "visão de baixo", portanto, não deve ser confundida com uma visão imune à crítica (HARAWAY, 1995, p.23). Frisa-se, neste ponto, a observação feita por Nancy Hartsock de que a standpoint theory deve ser "feminista", e não "feminina", tanto em razão do caráter conquistado dessa perspectiva, quanto, ao mesmo tempo, pelo seu potencial libertador (HARTSOCK, 1983, p.289).

Associada à noção de posição do sujeito está também a ideia de experiência, que pode ser compreendida, da forma como o faz Teresa de Lauretis, como "o resultado de um conjunto complexo de determinações e lutas, um processo de renegociações contínuas das pressões externas e resistências internas" (LAURETIS, 1990, p.137, tradução nossa). Como a 
própria identidade subjetiva, reconhece-se que a experiência está sujeita a inflexões das opressões múltiplas e interconectadas que têm lugar nos diversos contextos sociais e culturais. A experiência é, também, como mostrou Bartlett, socialmente compartilhada (BARTLETT, 2012, p.23 e 76), "interage com as percepções individuais presentes para revelar um novo entendimento e para ajudar ao indivíduo, junto a outros, a dar sentido a ditas percepções” (BARTLETT, 2012, p.104, tradução nossa). Nesses termos, conquanto a standpoint theory parta da construção de uma localização objetiva da vida das mulheres, a experiência individual não deve constituir seu elemento isolado e suficiente, devendo, ao contrário, estar qualquer consideração nesse sentido intrinsecamente vinculada à concretude e dinamicidade da democracia (HARDING, 1991, p.123). Significa dizer que é somente a partir das pressões, das determinações e das lutas vivenciadas por sujeitos submetidos a posições sociais semelhantes em determinada sociedade, caso das mulheres, que se tem a construção das experiências coletivas passíveis de transformar a produção dos saberes que envolvam os fatos sociais de que fazem parte.

A concepção epistemológica da teoria sustenta-se no reconhecimento de que a posição social ocupada pelo sujeito, lugar a partir do qual ele enxerga o mundo, embora sempre atravessada por opressões e tensões múltiplas (COSTA, 2002, p.87), influencia a sua percepção da realidade. A consequência é a admissão de que a posição do sujeito oprimido por uma estrutura marcada pela desigualdade permite, justamente em razão das experiências de discriminação e/ou de silenciamento de suas narrativas e perspectivas, que ele possa fornecer uma visão mais apurada das relações de poder em que se insere. Todo sujeito do conhecimento vê e fala de algum lugar e sua posição é marcada pelo seu gênero, pela sua classe, pela sua raça, pela sua orientação sexual, entre outros. Logo, quanto mais pontos de vista parciais puderem ser reunidos, especialmente em sociedades plurais e desiguais, maior o aperfeiçoamento da produção dos saberes e maior a probabilidade de se construir "conhecimento potente para a construção de mundos menos organizados por eixos de dominação” (HARAWAY, 1991, p.192).

A partir da standpoint theory, Harding, Haraway e Hartsock propõem a ampliação da objetividade na produção de conhecimento por meio da inclusão dos fatores sociais, historicamente rejeitados da metodologia científica por serem considerados inferiores e óbices ao 
atingimento do "verdadeiro" conhecimento. Harding chama essa ideia de "objetividade forte” (HARDING, 1991, p.138-164, tradução nossa), expressão que condensa com clareza toda a ideia proposta. A objetividade forte é aquela que depende tanto da expressa consideração da posição social de pessoas historicamente segregadas da produção do conhecimento, quanto do obrigatório reconhecimento, epistemológico e ético, por parte dos produtores de conhecimento, de sua localização enquanto sujeitos histórica e socialmente situados (HARDING, 2004, p.45). Haraway, ao tratar do que ela denomina "saberes localizados" (HARAWAY, 1995, p.18), está propugnando a mesma ideia, que é a construção de uma objetividade que parta do reconhecimento da específica e particular corporificação dos sujeitos (HARAWAY, 1995, p.21). Sem ignorar, portanto, todo o problema de se falar em objetividade e em verdade, opta-se, com Harding e Haraway, pela manutenção crítica do uso desses conceitos. Assume-se, assim, com base na standpoint theory, tanto que a verdade é situada, já que emerge de implicações e relações particulares (BARTLETT, 2012, p.104, tradução nossa), quanto que a aproximação da objetividade depende justamente da explicitação do ponto de partida de onde "se observam e se analisam os fatos e as ideias" (FACIO, 2000, p.20).

Concluindo, ao argumentar, como o faz Haraway, em favor do conhecimento como um feixe de "saberes parciais, localizáveis e críticos" (HARAWAY, 1995, p.23), a standpoint theory acolhida neste trabalho passa a justificar que se leve em conta, em todas as áreas do conhecimento, as perspectivas críticas das mulheres, sob pena de uma mitigação da objetividade perseguida. Essa proposta não pode ser confundida com uma visão que reforce a contraposição dualista ou mesmo adversarial do tipo mulheres versus homens, ou nós versus eles, como algumas críticas da teoria chegam a sustentar. Não se trata de forjar uma divisão social, nem de almejar uma desigualdade que, em uma inversão dos polos da opressão, passe a favorecer as mulheres. O argumento de que a defesa das perspectivas das mulheres reforçaria a divisão entre gêneros, além de simplificar a realidade da opressão - já que ocultar ou silenciar confrontos sociais não gera, evidentemente, a redução da discriminação -, é, no mínimo, pernicioso. A consequência, longe de ser o alcance da igualdade, é a resistência aos processos de libertação e de autodeterminação de 
grupos oprimidos, já que a afirmação identitária passa, necessariamente, pelo reconhecimento das diferenças.

\section{Perspectivas de mulher(es)}

Importante, neste ponto, perceber que ao se falar em perspectiva de mulheres - ou de grupos oprimidos - não se está definindo, ou postulando, um único ponto de vista, essencializado e universal, que oculte as tensões, as contradições, as multiplicidades e as diferenças irredutíveis a uma ilusória figura prévia, inequívoca e inconfundível de mulher - ou de outra coletividade subalternizada. Não é possível adotar uma teoria feminista de racionalidade e de objetividade (HARAWAY, 1995, p.25) que critique o universalismo e a abstração cerceadores da livre vivência dos sujeitos, mas se satisfazer, contraditoriamente, com uma uniforme e unívoca ideia de feminino. Ao contrário, entende-se, junto com Haraway, que a multiplicidade e a abertura dos sujeitos à contingência crítica da sua própria posição são imprescindíveis à concretude dos saberes localizados: "O eu dividido e contraditório é o que pode interrogar os posicionamentos e ser responsabilizado, o que pode construir e juntar-se a conversas racionais e imaginações fantásticas que mudam a história” (HARAWAY, 1995, p.26).

Por outro lado, apesar de ninguém duvidar que as mulheres não são absolutamente iguais entre si, é também inequívoco, como observaram Martin, Reynolds e Keith, que o sistema social de hierarquização de gênero desvaloriza, a um só tempo, toda a ideia de feminino, de modo que "todas as mulheres compartilham, até certo grau, um status ou posição menos privilegiada em relação aos homens" (KEITH; MARTIN; REYNOLDS, 2002, p.667, tradução nossa). Keith, Martin e Reynolds realizaram um trabalho empírico, baseado nas premissas teóricas da standpoint theory, em que buscaram analisar se um Judiciário composto exclusivamente por homens difere-se, em razão das distintas posições sociais produzidas no sistema sexo/gênero, de um que respeite uma certa paridade entre homens e mulheres (KEITH; MARTIN; REYNOLDS, 2002, p.667). A pesquisa, que envolveu mais de 2000 juízes e advogados homens e mulheres, com distintas raças/etnias, idades, posições na profissão jurídica e estados civis, demonstrou que as diferenças de perspectivas entre homens e mulheres em relação a 
desigualdades de gênero não são eliminadas quando consideradas outras variáveis de status (KEITH; MARTIN; REYNOLDS, 2002, p.689). Na conclusão apresentada pelos autores: "a conexão entre experiências com vieses de gênero e uma consciência feminista é penetrante e relativamente forte para mulheres e ausente ou fraca para homens" (KEITH; MARTIN; REYNOLDS, 2002, p.689, tradução nossa). Isto é, a despeito da diversidade identitária existente dentro de cada gênero, é possível observar, de forma mais significativa do que em relação aos homens, uma identificação recíproca das perspectivas de gênero entre mulheres.

Segue-se, nesse aspecto, a posição de Fraser (1997), para quem a ideia da não abrangência, pela categoria "mulher", de toda a multiplicidade "das mulheres" pode ser interpretada de duas maneiras: uma forte, porém indefensável, e outra fraca, e possível, porém insuficiente para a resolução do problema (FRASER, 1997, p.218). A primeira interpretação é a da impossibilidade completa de se falar em mulheres, já que, sendo pautado pela diferença e pela não identidade, o termo não poderia jamais ser definido. Essa tese forte, concorda-se com Fraser, apresenta dois problemas. Em primeiro lugar, é paradoxal, já que a própria indefinição do termo é, em si, uma forma de defini-lo. Em segundo lugar, é também inútil, já que, se, por um lado, não justifica o porquê de justo a ideia de "mulher" ou de "mulheres" merecer o signo do não idêntico e indefinível, por outro, todas as formas de denominações coletivas também carregariam tal negação: "não há nenhuma relação privilegiada entre a denominação 'mulheres' e o que é, na verdade, o problema político geral de como construir culturas de solidariedade que não são homogeneizantes e repressivas” (FRASER, 1997, p.218, tradução nossa).

A segunda tese, e mais defensável, é a consideração da contextualidade, da historicidade, do não fundacionalismo e da falibilidade de qualquer definição de "mulher" ou "mulheres", sem que tal justifique, porém, a inviabilização de uma categoria identitária. Isto é, trata-se, concomitantemente, do reconhecimento da inevitabilidade da generalização da categoria mulher e da sua permanente abertura a revisões, o que, embora se apresente epistemologicamente adequado e útil como categoria política, também não é suficiente para exaurir o problema, por não elaborar nem oferecer soluções para os conflitos reais existentes entre mulheres de diferentes classes, etnias, nacionalidades e orientações sociais (FRASER, 1997, p.218). Assim, conclui-se justamente com Fraser, a 
melhor situação parece ser a rejeição da antítese entre identidade e diferença - "feministas precisam, ao mesmo tempo, da desconstrução e da reconstrução, da desestabilização de significado e da projeção de uma esperança utópica” (FRASER, 1997, p.219, tradução nossa) - e a adoção de uma ideia de subjetividade que é, ao mesmo tempo, construída culturalmente e dotada de capacidade crítica (FRASER, 1997, p.219).

Em relação ao direito, o reconhecimento da total incompletude, fragmentação e pluralidade identitárias igualmente não se mostra postura adequada, dado que esse ramo da ciência social aplicada se sustenta justamente em categorias normativas e na pretensão da estabilidade jurídica. Não se pode ignorar que o gênero continua sendo também uma categoria relevante social e politicamente, já que cotidianamente considerado como um fator de discrímen destacado. E mais, com relação ao aprofundamento dos direitos fundamentais e humanos, a renúncia a toda e qualquer forma de categorização fundada no gênero é fator que obsta o próprio movimento rumo à igualdade "evitando o controle da maneira por meio da qual a vida e a subjetividade das mulheres e dos homens são moldadas pelo discurso e pelas práticas da hierarquia de gênero" (EICHNER, 2001, p.31, tradução nossa).

A situacionalidade, desse modo, nunca é óbvia, natural ou singular, mas um lugar de constante construção, como efeito dinâmico das inter-relações que a perpassam. As experiências vivenciadas individualmente não são feministas, nem femininas, de forma natural e essencialista. Ao contrário, as posições ocupadas pelas mulheres em uma dinâmica social excludente são contingentes, concreta e historicamente, e tanto a dinâmica quanto as posições se encontram em permanente conflito.

A standpoint theory de que trata o presente artigo não é, também, a afirmação de que o verdadeiro conhecimento advém exclusivamente de visões de mundo determinadas de sujeitos mulheres. Tal afirmação, em primeiro lugar, requereria, também, uma noção identitária fechada do sujeito "mulher", a despeito dos reconhecidos processos de produção da verdade pelo discurso e pelo poder e da exclusão que é imediatamente produzida a partir do ato de descrição abstrata, binária e essencialista dos sujeitos que são concretos e multifacetados (HARAWAY, 2009, p.47). Em segundo lugar, trata-se, obviamente, de uma noção em si excludente e, logo, opressora. A standpoint theory ora proposta é, ao contrário, a que 
reconhece que os conhecimentos, por serem sempre corporificados e situados social e historicamente, são, de forma irrecusável, também parciais, e não estão imunes à crítica, ao debate e à hermenêutica.

Esse reconhecimento não implica, no entanto, a afirmação da impossibilidade de que, em cada caso concreto, e a partir de um referencial normativo, algumas perspectivas possam ser consideradas melhores do que outras. Não se sustenta, por conseguinte, a ideia de que todo conhecimento necessariamente reflete uma relação não universalizável e peculiar de uma porção de sujeitos em face de um objeto do conhecimento. Não se defende a premissa de que é impossível atingir uma visão mais objetiva de um fenômeno do que aquela visualizada a partir de sua própria perspectiva (ANDERSON, 2004, p.10). Essas afirmações, no que se põe de acordo com Harding, são "más leituras ordinariamente feitas" (HARDING, 2001, p.512, tradução nossa) pelos críticos da standpoint theory.

A incompreensão se dissipa pela observação de que os conhecimentos localizados não são incomensuráveis, isto é, não são só as mulheres que podem compreender a luta contra a opressão de gênero. Ao contrário, trata-se de conhecimentos racionalizáveis, transmissíveis, comunicáveis, publicizáveis, isto é, passíveis de serem compreendidos e veiculados por sujeitos que não estejam posicionados no lugar de que partem as respectivas perspectivas. Nenhum impedimento há, portanto, para um homem ser feminista. Nos termos expostos por Uma Narayan, o que a standpoint theory destaca é que é "mais fácil e mais plausível para os (as) oprimidos (as) ter uma percepção crítica sobre as condições de sua própria opressão do que para os (as) que vivem fora dessa estrutura" (1997, p.285).

O foco nas perspectivas dos oprimidos, como se tratou acima, é justificado em razão da vivência direta, por esses sujeitos, dos mecanismos de negação (HARAWAY, 1995, p.23) e de silenciamento da repressão. Essa localização social torna os sujeitos em situação de sujeição mais aptos a reconhecer dinâmicas de exclusão e estruturas desiguais, permitindo-lhes trazer, por consequência, e em princípio, um maior potencial de críticas direcionadas ao estado presente da sociedade e das ideias nela produzidas. Isto é, o fato de se estar localizado em determinada posição social facilita que se produzam significados específicos em relação a fatos, ações e regras sociais, o que, por sua vez, está relacionado com determinadas experiências e interpretações particulares dos processos sociais (YOUNG, 
2006, p.162). Nesses termos, o debate e compartilhamento das perspectivas e a busca por soluções mais adequadas a problemas não são negados pela ideia de conhecimentos situados. Nada obsta, assim, que as perspectivas passíveis de serem acessadas diretamente por mulheres, em função da situação de subordinação social a que estão sujeitas, sejam dialógica e empaticamente compartilhadas com os homens. Vale ilustrar de outro modo, um homem pode compreender o machismo, assim como uma pessoa branca, o racismo, sendo necessárias apenas condições favoráveis ao compartilhamento dos pontos de vista parciais dos sujeitos oprimidos.

Outra questão importante na proposição feita, e que deve ser frisada, é que não se persegue aqui uma negação da própria possibilidade de produção do conhecimento, muito embora se reconheça a fragilidade de qualquer afirmação absoluta de uma ideia de verdade. A proposta é, desse modo, a assunção de uma produção de conhecimento que não seja nem relativista, nem arbitrária [ou totalizante, como coloca Haraway (1995, p.23)]. Se, de um lado, busca-se o discernimento entre um melhor e um pior entendimento, por outro não se admite uma verdade única, final ou objetiva, e, por isso, a opção pelos saberes localizados, parciais e críticos: "não ausência de perspectivas - somente perspectivas melhoradas” (BARTLETT, 2012, p.111, tradução nossa). As verdades ou saberes produzidos, importantes e não arbitrários, estão necessariamente imbricados às experiências, dinâmicas sociais e inter-relações humanas (BARTLETT, 2012, p.111). Centra-se, assim, na necessidade de se desconstruir a ideia, decorrente do relativismo, de que ou se tem uma verdade única (originada de um sujeito cognoscente universal) ou uma verdade impossível, que não é nada mais do que uma "maneira de não estar em lugar nenhum, mas alegando-se que se está igualmente em toda parte" (HARAWAY, 1995, p.24). O desafio posto a partir dessas considerações é o de aliar o reconhecimento da contingência histórica e social incidente sobre todo conhecimento a um compromisso com a busca por explicações não relativistas de um mundo que possa ser, nas belas palavras de Haraway, "parcialmente compartilhado e amistoso em relação a projetos terrestres de liberdade finita, abundância material adequada, sofrimento reduzido e felicidade limitada" (HARAWAY, 1995, p.16).

Entre as contribuições relevantes da standpoint theory para a questão da presença de indivíduos subalternos nos espaços de poder está, 
desse modo, o reforço ao questionamento da ideia de um sujeito universal capaz de compreender e acessar um conhecimento objetivo e neutro. A esse questionamento se alia a proposição de uma nova construção de conhecimento por sujeitos que se reconhecem, que não temem se admitir socialmente situados e que, exatamente por isso, são responsáveis por buscar maior pluralidade e diversidade de fontes na construção dos saberes. Vale dizer, não se propõe uma forma de conhecimento que seja neutra e universal no lugar de outra que mereceu exatamente essa crítica, nem se duvida que uma nova epistemologia é também uma nova relação entre saber e poder. Como sintetizou Smart, o que se busca é a revelação da exclusão das mulheres e a exigência de que "tanto o Estado quanto o direito respondam a nosso conhecimento, cientificamente verificável, acerca destas vidas" (SMART, 200o, p.53, tradução nossa). Diferente de defender, ou de se sobrevalorizar, uma perspectiva exclusivamente feminina, trata-se de incorporar às formas de produção de conhecimento dimensões que tendem a ser esquecidas em sociedades em que as mulheres se apresentam desigualmente empoderadas. Em suma, o que se enfrenta é justamente a hegemonia, a univocidade e qualquer pretensão totalizadora de interpretação do mundo.

Voltar a atenção para os conhecimentos situados e, consequentemente, para a relevância do gênero na produção dos saberes significa permitir tanto que velhas questões sejam reformuladas, e permitam respostas até então impensadas, como que novas questões, ignoradas e difíceis, sejam pensadas e levantadas (ANDERSON, 2004, p.10). Uma dessas questões é justamente sobre o que se perde, em uma democracia, com a presença preponderantemente masculina ou fortemente minoritária de mulheres na arena pública. A compreensão do saber localizado e da realidade generificada em que vivemos permite, assim, um aprofundamento da discussão em prol de uma sociedade mais livre e igualitária - a democratização da democracia (SANTOS; AVRITZER, 2002, p.67) -, motivo que torna a standpoint theory extremamente pertinente ao debate sobre inclusão democrática nos espaços de poder. 
918 | Veritas | Porto Alegre, v. 62, n. 3, set.-dez. 2017, p. 904-933

\section{Standpoint theory e teoria democrática: mulheres nos espaços de poder}

A standpoint theory apresenta importantes implicações políticas que têm sido, direta ou indiretamente, exploradas na teoria democrática por autoras feministas que confrontam a noção hegemônica de representação e discutem a diversidade de gênero no exercício dos poderes. Young, Phillips, Mansbridge e Fraser são autoras que, debruçando-se profundamente sobre a questão da exclusão de indivíduos e de grupos sociais subalternos do poder, foram capazes de fornecer, em conjunto, um importante referencial da aplicação dessa discussão à teoria democrática. É interessante observar que a standpoint theory pode ser encontrada, ainda que não mencionada expressamente, na discussão empreendida por todas as quatro autoras. Em Young, a premissa da standpoint theory é observada em sua utilização, nas discussões sobre representação de minorias, da noção de perspectiva social, que define, claramente, como o fato de que "pessoas diferentemente posicionadas têm diferentes experiências, histórias e compreensões sociais, derivadas daquele posicionamento" (YOUNG, 2006, p.162). Em Phillips, a mesma ideia é veiculada nos estudos sobre a igualdade no regime democrático, em que argumenta que uma distribuição mais plural de postos de poder tem o condão de trazer "uma maior gama de perspectivas para o jogo" (PHILLIPS, 1999, p.40, tradução nossa). Mansbridge (1999) revela sua afinidade teórica com a standpoint theory ao se propor discutir a questão da necessidade de negros representarem politicamente negros e mulheres representarem mulheres. A afinidade teórica está bem explicitada em seu argumento de que "a diversidade na representação (e a massa crítica de subgrupos importantes dentro dessa diversidade) em qualquer grupo descritivo aumenta muito as chances de perspectivas diversas serem representadas na deliberação" (MANSBRIDGE, 1999, p.647, tradução nossa). Finalmente, a standpoint theory pode ser identificada também em Fraser, em sua proposição dos "contrapúblicos subalternos”, por serem eles entendidos como espaços viabilizadores do compartilhamento de experiências comuns por sujeitos marginalizados em sociedades estratificadas, produzindo "contradiscursos que levam à formulação de interpretações antagônicas para suas identidades, interesses e necessidades" (FRASER, 1996, p.123). 
Observa-se, portanto, que, ainda que não o afirmem expressamente, as quatro autoras selecionadas deixam claro, cada uma ao seu modo, a relevância da proposição da standpoint theory para a discussão da diversidade social nos espaços de poder ao constatar que os conhecimentos situados fundamentam a necessidade de acesso de grupos socialmente excluídos a essas esferas. Reconhece-se, desse modo, que, de outra maneira, as perspectivas e experiências dos sujeitos que compõem esses grupos não serão completamente integradas aos debates públicos e, por consequência, deixarão de concretizar adequadamente a pluralidade de interesses, demandas e reivindicações da sociedade. Defende-se, portanto, nesta última seção deste artigo, que a inclusão de membros de grupos subalternizados ao poder é instrumento hábil a conduzir perspectivas, pois possui o condão de veicular conhecimentos e visões sobre as dinâmicas dos processos sociais silenciados e desconhecidos na discussão e na deliberação políticas. Além disso, tal inclusão nos espaços de poder permite jogar luz sobre processos históricos de opressão e suas relações com as coletividades, o que traz por consequência a desnaturalização das perspectivas dominantes. Abre-se, desse modo, espaço para que se descubram novas causas para os problemas enfrentados coletivamente (YOUNG, 2000, p.145) e para que se construam distintas possibilidades de enfrentamento.

A proposta que harmoniza a standpoint theory com a inclusão na esfera pública de grupos subalternos, de forma crítica e não essencializada, é a que visa representar perspectivas, já que essas, assim como os interesses e as opiniões, possuem em comum a circunstância de poderem ser politicamente representados. Diferentemente dos interesses e opiniões, porém, as perspectivas não definem ou cristalizam identidades, já que veiculam apenas pontos de vista e experiências decorrentes de distintas posições sociais. Vale colher os elementos dessa distinção conceitual entre representação, perspectivas, interesses e opiniões em Young:

Representar um interesse ou uma opinião geralmente envolve promover certos desdobramentos específicos no processo de tomada de decisões, ao passo que representar uma perspectiva geralmente significa promover certos pontos de partida para a discussão. A partir de uma determinada perspectiva social um representante coloca certos tipos de questões, relata certos tipos de experiência, retoma uma determinada linha de narrativa 
histórica ou expressa um certo modo de olhar as posições de outrem. Isso contribui decisivamente para a inclusão de diferentes pessoas no processo de tomada de decisões e chama a atenção para possíveis efeitos das políticas propostas sobre os diferentes grupos. No entanto, expressar uma perspectiva quase nunca significa inferir uma conclusão sobre resultados (YOUNG, 2006, p.167-168).

O saber situado se distancia do interesse e da opinião na medida em que, diferente de apresentar um conteúdo rígido e predeterminado, funciona como uma confluência de questões, experiências e pressupostos por meio dos quais "mais propriamente se iniciam raciocínios do que se extraem conclusões" (YOUNG, 2006, p.163). O compartilhamento de uma posição social significa, assim, um entendimento mais fácil de um modo de compreender os processos sociais, uma maior afinidade com a forma como a experiência é descrita (MANSBRIDGE, 1999, p.163-164) e um certo condicionamento que a maneira de olhar eventos sociais produz, sem, no entanto, determinar o que se vê (YOUNG, 2006, p.166). As vantagens desse tipo de compartilhamento, porém, como demonstra Phillips, são frequentemente esquecidas nos debates sobre a democracia, principalmente em razão de uma restritiva concepção de diferença, pelo discurso dominante, como divergência de ideias, crenças, opiniões, preferências e/ou objetivos, cingindo-se a representação à sua mera condição de veículo (PHILLIPS, 2001, p.268 e 272-273).

A representação de grupos sociais subalternos por indivíduos socialmente situados de maneira semelhante é especialmente mais vantajosa em situações sociais específicas em que se pode supor a alta improbabilidade de um corpo político, composto majoritariamente por sujeitos provenientes de posições sociais dominantes, definir como proposições prioritárias aquelas que decorram das perspectivas sociais de oprimidos. Young sugere, dentre essas situações, duas que justificam, prioritariamente, a preocupação com o acesso de grupos sociais subalternos ao poder. Em primeiro lugar, a existência de um "histórico de exclusão ou de afastamento de determinado grupo da influência política" (YOUNG, 2000, p,144, tradução nossa), com destaque para um estado de desinteresse ou de recusa, de forma disseminada, por parte de membros desse grupo, de atuarem positivamente nos espaços públicos como consequência desse passado de silenciamento. Em segundo lugar, estão as situações sociais em que prevalece a ideia de que determinadas 
perspectivas, exatamente as que controlam a discussão pública, que definem as prioridades políticas e que monopolizam as tomadas de decisões, são neutras e universais (YOUNG, 2000, p.144).

Mansbridge supera Young neste ponto da discussão, identificando mais situações sociais que justificam a discussão proposta. A primeira são os contextos de desconfiança, em que a qualidade da comunicação entre grupos é fragilizada em decorrência de um histórico social de dominação e de subordinação social. Também sensíveis são as realidades sociais em que se instauram contextos de dúvida, em que os interesses dos grupos ainda não estão totalmente sedimentados e articulados, tornando especialmente relevante que experiências sejam compartilhadas e exploradas. Igualmente importantes são os contextos em que a capacidade de participação política de determinado grupo não está consolidada no imaginário coletivo, o que ocorre, com frequência, quando aquela coletividade já foi excluída do poder na história política da sociedade. Finalmente, no mesmo sentido da primeira hipótese considerada por Young, deve-se atentar para contextos de histórica discriminação de grupos, com uma desproporcional presença de determinada coletividade nos espaços de poder (MANSBRIDGE, 1999, p.634 e 641-652).

Outra forma sugerida pela autora é tentar responder a dois questionamentos em relação a características da população que esteja presente em proporções menores nos centros de poder do que na composição demográfica da sociedade. A primeira questão é se os membros desse grupo se consideram hábeis ou têm interesse de representar a si mesmos. A segunda é se existe evidência de que os grupos socialmente dominantes já em algum momento dificultaram ou tornaram ilegal que membros daquele grupo se fizessem presentes no poder (MANSBRIDGE, 1999, p.639, tradução nossa). Se presente algum dos contextos/aspectos anteriormente descritos, ou se a resposta para qualquer dessas questões for positiva, estar-se-á diante de um grupo cuja representação seletiva afirmativa apresenta-se legitimamente democrática.

A defesa da utilização desses mecanismos especiais de representação não significa, portanto, a sustentação de que seja desejável uma intervenção ou um desenho institucional que garanta que toda e qualquer característica de uma determinada população seja presentificada nos círculos de poder. Confunde-se, com essa ideia, dois modelos diversos 
de representação descritiva, o microcósmico e o seletivo (MANSBRIDGE, 1999, p.631-633). O modelo microcósmico pretende que os representantes figurem como uma exata amostra da população. Já a representação seletiva, aqui defendida, consiste na criação de mecanismos institucionais que garantam especificamente o acesso ao poder a grupos que são dele distanciados em razão de uma desigualdade social estrutural. A representação de coletividades somente é justificada, portanto, como pontuou Mansbridge, "quando alguma forma de seleção adversa operar em um sistema existente para reduzir a proporção de certos grupos abaixo do nível que eles iriam atingir por sorte” (MANSBRIDGE, 1999, p.632, tradução nossa). Nesses termos, inadequada a posição crítica que argumenta decorrer da representação descritiva a necessidade de acolhimento de toda e qualquer coletividade, já que não seria possível a definição de quais características mereceriam representação [esse o substrato do argumento levado ad absurdum quanto à suposta necessidade do acolhimento, por exemplo, "do grupo" dos canhotos, dos ruivos, dos judeus, dos italianos e dos analfabetos (MANSBRIDGE, 1999, p.634)]. A melhor resposta a esse problema, porém, não deve ser o abandono das profundas vantagens à democracia trazidas pela representação de grupos sociais subalternizados, conforme discutidas até aqui, mas sim o estabelecimento de um bom critério para a distinção entre casos que merecem representação e aqueles em que a representação seja simplesmente irrazoável.

Mansbridge apresenta como critério o atendimento, pelo grupo examinado, do que ela denomina funções deliberativas e agregativas da democracia (MANSBRIDGE, 1999, p.634). Em relação às funções deliberativas, a escolha de representantes deve ser tal que abranja todos aqueles - e somente aqueles - grupos que possam prover perspectivas relevantes para a tomada de decisões, excluindo-se, portanto, as visões inúteis ou prejudiciais à sociedade como um todo. Os processos deliberativos pressupõem manifestação de interesses de variados grupos sociais. Para tanto, deve ser dada voz aos sujeitos que estão, na sociedade, diferentemente posicionados, já que, por acessar perspectivas distintas, possuem melhores condições de reconhecer opressões, articular seus mecanismos e propor soluções (SACCHET, 2012, p.415). Já para atender à função agregativa da democracia, isto é, o atingimento de um certo nível de consenso social que se legitime no contexto de conflitos fundamentais 
de interesses, os representantes devem ser aqueles que idealmente possam representar todos os grupos cujas perspectivas estão em conflito na sociedade (esse requisito deve vir, inclusive, acompanhado de instrumentos de proteção dos direitos das minorias) (MANSBRIDGE, 1999, p.634).

A situação das mulheres no Brasil, hoje, configura hipótese perfeitamente justificada de representação de grupos subalternos nas esferas de poder. Primeiramente, por se tratar de um fato a histórica e atual opressão de gênero na sociedade brasileira, com a manutenção de altos índices de desigualdade em todas as esferas da vida pública e privada (context of distrust) (MANSBRIDGE, 1999, p.641). Em segundo lugar, dada a ausência de sedimentação e pacificação das questões de gênero na sociedade (contexts of uncrystallized interests), bastando-se levar em conta as constantes polêmicas públicas, jurídicas e políticas envolvendo, entre outros, o corpo das mulheres, o aborto, o assédio e a participação das mulheres na política (MANSBRIDGE, 1999, p.643). Em terceiro lugar, a inclusão feminina nos espaços públicos de poder é justificada tendo em vista o afastamento da mulher da vida pública e, especificamente, da participação política na história brasileira, seja pela demora no reconhecimento da equiparação dos direitos políticos entre homens e mulheres, já que somente em 1932 as mulheres tiveram o direito ao voto reconhecido no país (construction of social meaning) (MANSBRIDGE, 1999, p.648), seja pela permanência de relevante desproporção entre a presença de mulheres no poder e a sua composição na sociedade (de facto legitimacy) (MANSBRIDGE, 1999, p.650). A representação de mulheres se justifica, ainda, por ser o gênero um fator relevante de distinção social a atribuir status, poderes, vozes e posições opostas a homens e mulheres dentro da sociedade e por visar a luta de mulheres contra a própria condição de opressão o alcance da igualdade e da liberdade entre todos os indivíduos, premissa fundamental de um regime democrático.

O esforço voltado à ampliação da presença de mulheres nos espaços de poder se justifica, desse modo, como uma forma de facilitar a compreensão, o compartilhamento e a veiculação de perspectivas de metade da população brasileira. Essa parcela se encontra posicionada de forma desvantajosa na estrutura social em razão do gênero e, por decorrência dessa condição, é vítima de opressões, violências, silenciamentos e marginalização social. A ausência de instrumentos para 
a representação de mulheres, legando aos homens a condução das discussões e decisões públicas, faz com que perspectivas dominantes continuem a determinar com exclusividade as prioridades políticas, as causas e possíveis soluções dos conflitos e a interpretação dos significados dos fatos sociais, travestindo um modo específico de ver o mundo em uma visão pretensamente neutra e universal e frontalmente divorciada de uma democracia heterogênea, multipolarizada e plural.

Nesses termos, para combater os efeitos perversos da exclusão dos pontos de vista das mulheres na construção democrática das regras e práticas sociais, não é suficiente que homens possam representar interesses de mulheres. Assumir essa insuficiência não significa dizer, porém, como trabalhado na seção anterior, que o distanciamento de posições sociais torna impossível o compartilhamento de experiências e perspectivas. O que ocorre, na verdade, como a standpoint theory aponta, é que o fato de os homens não experimentarem as situações vividas por mulheres ou se situarem nos mesmos espaços e posições sociais dados pela desigualdade de gênero torna consideravelmente mais difícil que articulem perspectivas acessíveis pela opressão sofrida (PHILLIPS, 1998). Essa circunstância é especialmente verdadeira, como demonstra Mansbridge (1999, p.635), em contextos de desconfiança comunicativa e em relação a interesses não cristalizados na agenda pública, o que, como se mostrou, é o caso das mulheres no sistema sexo/gênero brasileiro.

A opressão e a desigualdade de gênero são realidades sociais e o seu enfrentamento somente surgiu a partir do momento em que mulheres se reuniram e passaram a nomear essa condição de subordinação e a apontar as violências e violações à igualdade e à liberdade. Os dados históricos justificam e tornam relevante, portanto, a implementação do princípio da participação paritária de gênero, porque desvelam meios e formas de confrontação de assimetrias de poder ilegítimas, provenientes, a um só tempo, de uma distribuição desigual de recursos e do falso reconhecimento institucionalizado proveniente de padrões depreciativos de ordem cultural (BERNARDES, 2014, p.337). Esse princípio paritário deve ser, obviamente, dado o marco democrático assumido, aplicado de forma dialógica e discursiva. É indispensável, pois, que a investigação quanto à existência de impedimentos, por parte das normas institucionalizadas, à consagração da paridade participativa seja feita pelos próprios sujeitos sociais provenientes de grupos excluídos, assim como 
seja a eles possível a identificação e a censura da introdução ou da exacerbação injustificadas de outras disparidades (FRASER; HONNETH, 2003, p.43).

Como se analisou, os espaços que reúnem mulheres permitem o reconhecimento recíproco dos elementos de subordinação social e das perspectivas de transformação. Amplia-se, assim, a possibilidade de que as mulheres vocalizem seus interesses na agenda política, levando-os à esfera pública hegemônica. A utilidade desses espaços, os contrapúblicos subalternos de Fraser, está também no reconhecimento da própria pluralidade ínsita à noção de mulheres, reunindo em sua diversidade (mulheres negras, mulheres lésbicas, mulheres transgêneras, mulheres trabalhadoras, etc) a variedade de perspectivas que pode exigir, inclusive, a formação de contrapúblicos subalternos dentro dos próprios contrapúblicos subalternos (FRASER, 1996, p.124). E ainda que sejam várias as posições ocupadas pelos sujeitos, a sobreposição de opressões em razão de fatores distintos como o gênero, a raça e a classe não inviabiliza a proposta da standpoint theory, ao contrário, permitindo aos sujeitos a obtenção de perspectivas mais apuradas sobre a dinâmica opressor/oprimido e sobre os mecanismos da opressão, o que, é razoável supor, favorece a compreensão dos processos sociais de exclusão.

A defesa da inclusão das mulheres, baseada na comunhão de perspectivas, não parte da suposição de que os membros de um mesmo grupo socialmente favorecido possuem os mesmos interesses, opiniões ou ideias sobre quaisquer temas. Como consequência, em primeiro lugar, está a admissão de que representantes mulheres não vão, de forma necessária e absoluta, garantir cada interesse ou opinião de todas as mulheres representadas. Assim como um representante liberal não vai, da mesma forma, fazê-lo em relação às opiniões e interesses dos liberais. O reconhecimento dessa impossibilidade não desconfigura, no entanto, a justificava central da proposta que é a existência de um contexto social que valora e posiciona todas as mulheres, disseminadamente, de forma subordinada aos homens.

A segunda consequência para o fato da pluralidade de interesses, opiniões ou ideias dentro de um mesmo grupo socialmente desfavorecido é justamente a necessidade de que a representação cuide de fazer presente a diversidade existente internamente à própria subalternização (MANSBRIDGE, 1999, p.639). Em outras palavras, imprescindível que se 
leve em conta o fato da interseccionalidade, que é a sobreposição, no mesmo indivíduo, de distintas formas de opressão. O reconhecimento da interseccionalidade permite evitar tanto a essencialização identitária dos grupos, combatendo a presunção de que todos os membros de uma coletividade compartilham integralmente idênticas perspectivas, quanto que a representação se faça ao custo do silenciamento e da opressão de vozes ainda mais minoritárias dentro de cada grupo. Acolhe-se, desse modo, aliás, o aprendizado do próprio feminismo enquanto movimento social, que, em seu desenvolvimento se deparou com o problema do questionamento de sua legitimidade por se ver construído, até então, com ênfase exclusiva nas experiências das mulheres brancas, heterossexuais e de classe média-alta. Isso significa dizer que, conquanto mulheres negras, mulheres brancas, mulheres pobres, mulheres ricas, mulheres heterossexuais, mulheres lésbicas, mulheres cisgêneras e mulheres transgêneras compartilhem de uma posição socialmente semelhante em razão da opressão de gênero, um grupo formado exclusivamente por mulheres brancas, ricas, heterossexuais e cisgêneras não vai ser capaz de comunicar adequadamente a pluralidade de perspectivas das mulheres e, mais especificamente, a amplitude e a profundidade das opressões existentes na sociedade.

Em síntese, a consideração da localização social semelhante das mulheres em sociedades pautadas pelo sistema sexo/gênero não elimina as relevantes diferenças internas existentes nesse grande grupo, permanecendo a sobreposição de opressões que sofrem, por exemplo, mulheres negras e/ou pobres e/ou lésbicas e/ou transgêneras. O reconhecimento das decorrências da standpoint theory não significa ignorar que os indivíduos em sociedades complexamente estruturadas estão posicionados em face de múltiplas relações entre grupos diferenciados, o que produz também uma multiplicidade de perspectivas sociais que podem se encontrar, entrecruzar-se ou sobrepor-se, admitindo-se que os indivíduos entre elas transitem de acordo com as pessoas com as quais interagem ou o aspecto da realidade social que observam/interpretam (MANSBRIDGE, 1999, p.650). Tais razões, como sustenta Young, não podem conduzir, contudo, a uma negação da possibilidade de criação de canais para a expressão de vozes abafadas, mas, sim, servir para aperfeiçoá-los, repudiando-se, assim, a representação meramente simbólica, que se satisfaz com a garantia de um representante 
alçado à condição de porta-voz de uma multiplicidade dissimulada em unidade. Ao contrário, a representação das perspectivas das mulheres será sempre mais efetiva quanto maior o número de mulheres representantes, admitindo-se o acolhimento de diferenças de perspectivas que perpassam o grupo e dando maior alcance à representação ao pluralizá-la (YOUNG, 2006, p.180).

Harmonizam-se, desse modo, a noção de paridade participativa e de contrapúblicos subalternos com a ideia de representação de mulheres e da standpoint theory, já que convergem todas elas para o reconhecimento de que o processo de construção democrática dos discursos depende do encontro de mulheres e da partilha de suas experiências comuns decorrentes da sua posição estruturalmente subordinada em sociedades pautadas pelo sistema sexo/gênero. A formação dos contradiscursos aos discursos dominantes surge, assim, da concreta partilha, entre mulheres, de perspectivas e necessidades que se identificam pela situação de desigualdade compartilhada.

A discussão ensejada por Young, Phillips, Mansbridge e Fraser, no contexto de sociedades marcadas pela opressão estrutural das mulheres do sistema sexo/gênero, tem como consequência a necessidade de um rearranjo das esferas públicas brasileiras, só em tese universalmente inclusivas. Acolhe-se, nesse sentido, a conclusão de Phillips:

(...) onde igualdades estão vinculadas à diferença de grupos, arranjos políticos (e legais) podem ter considerável força corretiva. Reformas políticas não podem substituir inteiramente reformas sociais e econômicas, mas podem certamente prover as condições favoráveis para isso (PHILLIPS, 1999, p.30, tradução nossa).

A justa distribuição de posições de poder em função do gênero em sociedades em que as posições sociais são estruturalmente ocupadas de forma desigual em razão desse critério é um passo importante para o reequilíbrio de forças na esfera pública e para a eliminação das assimetrias de poder entre homens e mulheres. Essa medida de justiça abrange necessariamente a asseguração da existência, em condições de igualdade, de representantes homens e mulheres que possam dar voz às demandas abafadas ou silenciadas entre os representados por falhas de distribuição e de reconhecimento. Busca-se, a partir disso, viabilizar a posição das mulheres como pares nas interações discursivas com os homens e, por 
consequência, garantir que as preocupações, as reivindicações e as perspectivas decorrentes de suas vivências sejam também alçadas ao centro da esfera pública. Essa atuação, para efetivamente concretizar o princípio da paridade participativa, deve ser realizada de forma quantitativa e qualitativamente semelhante à presença dos homens nesses espaços, que, por sua vez, devem ser todos os lugares em que eles exerçam poder.

Dentro desses espaços de representação devem ser garantidos, ainda, os contrapúblicos subalternos, aí caracterizados pela presença das mulheres em número relevante o suficiente à criação de um espaço favorável para se produzir e se fazer ouvir os contradiscursos aos discursos dominantes no âmbito da própria representação. A preocupação com a garantia de uma quantidade relevante de representantes mulheres também visa a assegurar, como visto, a maior pluralidade e diversidade identitária possível, de modo a impedir a essencialização e a cristalização da identidade feminina.

A noção de representação de grupos subalternizados, liberta da ideia de representação como substituição ou como identificação e qualificada pela garantia dos contrapúblicos subalternos, favorece, dessa maneira, a paridade participativa entre homens e mulheres nas instâncias de poder. A proposta confronta a ideia, tipicamente utilizada pelos opositores das ações afirmativas, de que a justiça requer a limitação do reconhecimento público às capacidades que todos os seres humanos compartilham. Ao contrário, admite-se que o acolhimento do que distingue as pessoas umas das outras pode ser justamente o que vai gerar o rompimento dos obstáculos existentes à concretização da igualdade de participação dos sujeitos na construção de seu destino (FRASER; HONNETH, 2003, p.46).

O que o reconhecimento da existência de perspectivas/localizações do saber e das multiplicidades e contradições na produção do conhecimento (HARDING, 1991) não pode almejar, de modo algum, é ser algo fixo, acabado e isento de conflitos. Assim como não é "tranquilizador"5 reconhecer as contradições e imprevisibilidades do exercício do poder democrático e constatar que a democracia concreta se

\footnotetext{
5 Refiro-me aqui diretamente à rasa crítica de Susan Haack a Harding: "Sandra Harding conta-nos que é de se esperar que a epistemologia feminista venha a 'conter contradições', que se trata de um 'conhecimento múltiplo e contraditório' a partir do qual devemos ‘aprender e pensar'. Isso não é muito tranquilizador” (HAACK, 2011, p.203).
} 
ergue necessariamente a partir de saberes parciais e múltiplos. A admissão de que as sociedades são heterogêneas, complexas e marcadas pelo pluralismo (CITTADINO, 200o, p.2) torna perigoso e danoso pautar qualquer construção humana em um parâmetro de sujeito abstrato, universal e livre das contingências das diferenças. Essa constatação, de fato, não evita, e nem se propõe evitar, as incertezas, o conflito e a imprevisibilidade. O que se propõe é que, reconhecida a inequivocidade da diversidade de experiências e da interseccionalidade, observe-se também as similitudes mútuas, "o conhecimento do indivíduo e da comunidade, aparte e necessariamente interdependente” (BARTLETT, 2012, p.113, tradução nossa).

A representação proposta acolhe a contribuição da standpoint theory de que "agentes que estão 'próximos' no campo social possuem pontos de vista semelhantes sobre esse campo e sobre o que ocorre em seu âmbito, enquanto aqueles que estão socialmente distantes tendem a ver as coisas de modo diverso" (YOUNG, 2006, p.162-163). Estar situado socialmente de forma semelhante enseja, assim, uma perspectiva social comum, o que significa a adoção, não de uma lógica substancial, mas de uma lógica relacional de presença/representação (YOUNG, 2006, p.161). Como sustentou Phillips, "é no relacionamento entre ideias e presença que nós temos mais chances de encontrar um sistema mais justo de representação" (PHILLIPS, 1998, p.25, tradução nossa). Em suma, reconhecendo-se, juntamente com Fraser, como princípio básico de justiça democrática, que nenhum ponto de vista pode ser excluído a priori do debate e que todo consenso será provisório e sujeito à revisão sob novos argumentos (FRASER; HONNETH, 2003, p.43 e 77-78), mostra-se relevante que os desenhos institucionais e as normas institucionalizadas promovam a presença de mulheres, em condições não simbólicas, nos espaços de poder. Só assim será possível almejar a concretização, na esfera pública ampla, da paridade participativa entre homens e mulheres, promovendo, assim, a desconstrução da condição social subordinada em razão do gênero.

\section{Referências}

ANDERSON, Elizabeth S. Feminist epistemology and philosophy of science. In: ZALTA, Edward N. The Stanford Encyclopedia of Philosophy, 2004. 
930 | Veritas | Porto Alegre, v. 62, n. 3, set.-dez. 2017, p. 904-933

BARTLETT, Katharine T. Métodos Juristas Feministas. In: MORALES, Félix; FERNANDEZ, Marisol. (Orgs.) Métodos feministas em el derecho: aproximaciones criticas a la jurisprudência peruana. Lima: Palestra, 2012, p. 19-116.

BEAUVOIR, Simone de. O Segundo Sexo. Tradução de Sérgio Milliet. 2. ed. Rio de Janeiro: Editora Nova Fronteira, 2009.

BERNARDES, Márcia Nina. Violência doméstica, opressão de gênero e justiça social: uma análise da Lei 11340/o6 a partir do princípio da paridade de participação. In: CASTRO, Matheus Felipe de; AMAYA, Lidia Patricia Castillo (Orgs.). Teoria Crítica do Direito: XXIII Encontro Nacional Conpedi. 1. ed. Florianópolis: Conpedi, v. 1, 2014, p. 334-357.

CITTADINO, Gisele. Pluralismo, direito e justiça distributiva. Elementos da Filosofia Constitucional Contemporânea. Rio de Janeiro: Editora Lumen Juris, 2000.

COMTE, Augusto. Discurso sobre o espírito positivo. São Paulo: Abril, 1973.

COSTA, Claudia de Lima. O sujeito no feminismo: revisitando os debates. Cadernos Pagu, n. 19, p. 59-90, 2002.

DURKHEIM, Émile. As regras do método sociológico. São Paulo: Abril, 1973.

EICHNER, Maxine. On Postmodernist Feminist Legal Theory. Harvard Civil Rights- Civil Liberties Law Review (CR-CL), v. 36, n. 1, 2001. Disponível em: <http://harvardcrcl.org/wp-content/uploads/2015/o7/On-PostmodernFeminist-Legal-Theory.pdf>. Acesso em: 23 jul. 2017.

FACIO, Alda. Hacia outra teoria crítica del derecho. In: FRIES, Lorena; FACIO, Alda (Eds.). Género y derecho. Santiago: LOM Ediciones y la Morada, 2000.

FINE, Cordelia. Delusions of gender: how our minds, society, and neurosexism create difference. New York/London: W.W. Norton \& Company, 2010.

FLAX, Jane. Pós-modernismo e as Relações de Gênero na Teoria Feminista. In: HOLLANDA, Heloisa Buarque de. Pós-modernismo e Política. Rio de Janeiro: Rocco, 1992, p. 217250 .

FRASER, Nancy. Rethinking the Public Sphere: a Contribution to the Critique of Actually Existing Democracy. In: CALHOUN, Craig (Ed.). Habermas and the Public Sphere. Cambridge: MIT Press, 1996.

. Justice interrupts: critical reflections on the postsocialist condition. New York \& London: Routledge, 1997. 
M. F. Santos - A representação de mulheres nos espaços de poder e a standpoint theory | 931

FRASER, Nancy; HONNETH, Axel. Redistribution or Recognition: a Philosophical Exchange. Londres: Verso, 2003.

GROSZ, Elizabeth. Que és la teoría feminista? Debates Feministas, Mexico D.C., a. 6, v. 12, p.85-105, out. 1995 .

HAACK, Susan. Manifesto de uma moderada apaixonada: ensaios contra a moda irracionalista. Rio de Janeiro: Ed. Puc-Rio, 2011.

HARAWAY, Donna. Simians, Cyborgs, and Women: the Reinvention of Nature. New York: Routledge, 1991.

. Saberes localizados: a questão da ciência para o feminismo e o privilégio da perspectiva parcial. Cadernos Pagu, n.5, p.7-42, 1995. Disponível em: < https://periodicos.sbu.unicamp.br/ojs/index.php/cadpagu/article/view/1773>. Acesso em: 23 jul. 2017.

. Manifesto ciborgue: Ciência, tecnologia e feminismo-socialista no final do século XX. In: TADEU, Tomaz (Org.). Antropologia do ciborgue: As vertigens do pós-humano. 2. ed. Belo Horizonte: Autêntica Editora, 2009, p. 33-118.

HARDING, Sandra. Whose Science? Whose knowledge? Ithaca, NY: Cornell University Press, 1991.

. Comment on Walby's "Against Epistemological Chasms: The Science Question in Feminism Revisited": Can Democratic Values and Interests Ever Play a Rationally Justifiable Rome in the Evaluation of Scientific Work? Signs: Journal of Women in Culture and Society, v. 26, n.2, p. 511-525, 2001.

Introduction: standpoint theory as a Site of Political, Philosophic, and Scientific Debate. In: HARDING, Sandra (Ed.). The Feminist standpoint theory Reader: Intellectual and Political Controversies. New York: Routledge, 2004, p. 115.

HARTSOCK, Nancy. The Feminist Standpoint: Developing the Ground for a Specifically Feminist Historical Materialism. In: HARDING, Sandra; HINTIKKA, Merrill B (Eds.). Discovering Reality: Feminists Perspectives on Epistemology, Metaphysics, Methodology, and Philosophy of Science. Dordrecht: Kluwer Academic Publishers, 1983, p. 283-310.

HIRSH, Elizabeth; OLSON, Gary A. Starting from Marginalized Lives: A Conversation with Sandra Harding. JAC: A Journal of Composition Theory, v. 15, n.2, p.193-225, 1995.

JORDAN-YOUNG, Rebecca. Brainstorm: the Flaws in the Science of Sex Differences. Cambridge: Harvard University Press, 2010. 
932 | Veritas | Porto Alegre, v. 62, n. 3, set.-dez. 2017, p. 904-933

KEITH, Shelley; MARTIN, Patricia Yancey; REYNOLDS, John R. Gender Bias and Feminist Consciousness among Judges and Attorneys: A standpoint theory Analysis. Signs, v. 27, n. 3, p. 665-701, 2002.

LAURETIS, Teresa de. Eccentric Subjects: Feminist Theory and Historical Consciousness. Feminist Studies, v. 16, n.1, p. 115-150, 1990.

MANSBRIDGE, Jane. Should Blacks Represent Blacks and Women Represent Women? A Contingent "Yes"'. The Journal of Politics, v. 61, n. 3, p. 628-657, 1999.

NARAYAN, Uma. O projeto da epistemologia feminista: perspectivas de uma feminista nãoocidental. In: JAGGAR, Alison M.; BORDO, Susan. R. (Eds.). Género, corpo, conhecimento. Rio de Janeiro: Record: Rosa dos Tempos, 1997.

PHILLIPS, Anne. The Politics of Presence. Oxford: Oxford University Press, 1998. . Which Equalities Matter? Cambridge: Polity Press, 1999.

. De uma política de ideias a uma política de presença? Estudos Feministas, Florianópolis, v.9, n.1, jan. 2001.

PITKIN, Hanna Fenichel. The Concept of Representation. Londres: University of California Press, 1967.

RABENHORST, Eduardo. O feminismo como crítica do direito. Revista Eletrônica Direito e Política, v. 4, n.3, p. 22-35, 2009. Disponível em: < https://siaiap32.univali.br//seer/index.php/rdp/article/view/6141>. Acesso em: 23 jul. 2017.

. Encontrando a Teoria Feminista do Direito.Prim@ Facie, v. 9, p. 7-24, 2011.

Disponível em:

http://periodicos.ufpb.br/index.php/primafacie/article/view/9871>. Acesso em: 23 jul. 2017.

SACCHET, Teresa. Representação política, representação de grupos e política de cotas: perspectivas e contendas feministas. Revista de Estudos Feministas, v.20, n.2, p. 399-431, 2012. Disponivel em: <http://www.scielo.br/pdf/ref/v2on2/v20n2a04.pdf>. Acesso em: 07 ago. 2015.

SANTOS, Boaventura de Sousa; AVRITZER, Leonardo. Introdução: para ampliar o cânone democrático. In: SANTOS, Boaventura de Sousa. (Org.) Democratizar a democracia. Os caminhos da democracia participativa. Rio de Janeiro: Civilização Brasileira, 2002. 
M. F. Santos - A representação de mulheres nos espaços de poder e a standpoint theory | 933

SAYERS, Janet. Feminism and science - reason and passion. Women's Studies Int. Forum, v. 10, n. 2, p. 171-179, 1987.

SMART, Carol. La teoría feminista y el discurso jurídico. In: BIRGIN, Haydée (Org.). El derecho en el gênero y el gênero en el derecho. Buenos Aires: Editorial Biblos, 2000, p. 31-71.

YOUNG, Iris Marion. Inclusion and democracy. Oxford; New York: Oxford University Press, 2000.

. Representação Política, Identidade e Minorias. Lua Nova, São Paulo, v. 67, p.1-53, 2006.

\section{Endereço postal:}

Escola Superior Dom Helder Câmara Faculdade de Direito

Rua Álvares Maciel, 628 - Santa Efigênia, Belo Horizonte - MG, Brasil

Data de recebimento: 08-08-2017

Data de aceite: 04-12-2017 